\title{
8th International Congress on Science and Technology of Ironmaking-ICSTI 2018
}

\author{
Johannes Schenk ${ }^{1}$ and Bruno Hribernik ${ }^{2}$ \\ ${ }^{1}$ Chair of Ferrous Metallurgy, Montanuniversitaet Leoben, Leoben, Austria \\ ${ }^{2}$ Executive Member of the Managing Board, ASMET, Leoben, Austria
}

In this issue of the BHM Berg- und Hüttenmännische Monatshefte, selected articles of 8th International Congress on Science and Technology of Ironmaking, ICSTI 2018 are published. The Congress took place in Schloss Schönbrunn, Apothekertrakt, Vienna from 25 to 28 September, 2018, and brought together 300 experts coming from a wide range of fields, ranging from plant operation and plant suppliers to research institutes, sharing expertise in:

- Cokemaking

- Iron ore production and handling

- Sintering

- Pelletising

- Blast furnace ironmaking

- Direct reduction

- Smelting reduction

- Environmental control in coke and ironmaking

- $\mathrm{CO}_{2}$ reduction and energy saving

- Recycling of in-plant residues

- Automation and digitalization in coke and ironmaking

- Modelling and simulation in coke and ironmaking

In total, the conference contributions consisted of 162 oral presentations and 24 posters.

ICSTI 2018 focused on the core issues of the industrial production chain of ironmaking technologies. The scientific and technological goal was to present the state of the art of theoretical, experimental, and numerical techniques (and their combination) capable of improving the competitiveness of modern production facilities. We hope that the readers of this issue of the BHM get an impression of the diversity, quality, and timeliness of technical and scientific topics dealt with in the ICSTI 2018.

As organizers, we are proud to have been able to put together a unique meeting, by adding the flare of Vienna

\footnotetext{
J. Schenk $(\square)$

Chair of Ferrous Metallurgy,

Montanuniversitaet Leoben,

Leoben, Austria

johannes.schenk@unileoben.ac.at
}

to high quality science. We felt the conference was characterized by a stimulating and dynamic atmosphere and provided the conditions for an effective dialogue and exchange of ideas and insights. Many topics were covered, and the presenters did an outstanding job of sharing their expertise. We are extremely gratified that the conference attracted such a large number of authors and delegates from 29 countries: it confirmed an increasing willingness to respond with a proactive attitude towards the challenging economic situation in the iron and steel industry, seeking opportunities to meet, exchange, and learn from each other.

We are honoured to have sound scientific contributions covering various disciplines in all aspects of research, development, production technology in cokemaking and ironmaking, with approaches ranging from experimental processes to numerical modelling and simulation.

We would like to give once again special thanks to the Scientific Committee: Thomas Bürgler, voestalpine, Austria; José Adilson de Castro, Universidade Federal Fluminense, Brasil; Yakov Gordon, Hatch, Canada; SungMo Jung, Pohang University of Science and Technology, Korea; Hans-Bodo Lüngen, VDEh, Germany; Aloísio Simões Ribeiro, RHI Magnesita, Brasil; Merrick Mahoney, University of Newcastle, Australia; Barada Kanta Mishra, At-Goa College of Engineering, India; Manoj Kumar Mitra, Jadavpur University, India; José Noldin, Lhoist, Brasil; Hanspeter Ofner, Primetals Technologies Austria $\mathrm{GmbH}$, Austria; Koji Saito, NSSMC Research \& Development, Japan; Noritaka Saito, Kyushu University, Japan; Peter Schmöle, Thyssenkrupp, Germany; Elmar Schuster, voestalpine, Austria; Yongzhi Sha, CSM, Ironmaking Branch, China; Du Sichen, KTH Royal Institute of Technology in Stockholm, Sweden; Lena Sundquist Öqvist, Swerea MEFOS AB, Sweden; Markku Vetoniemi, SSAB Europe Oyj, Finland; Tianjun Yang, University of Science and Technology Beijing, China; Sang-Ho Yi, POSCO, FINEX Ironmaking, Korea; Lifeng Zhang, University of Science and Technology, Beijing, China and all our sponsors for their financial support. 
We would also like to express our special gratitude to all speakers, chairpersons, and participants.

All parties involved have conjointly made it possible for us to stage such an international event. Finally, we also want to express our immense gratitude to the conference managers Melanie Baumgartner and Yvonne Dworak as well as to our IT manager Ziad Babilli for all their professional work in the conference organization; without their support and kindness, this conference would not have been possible. If you would like to buy the complete e-book of ICSTI 2018, please contact: lisa.loeschnauer@asmet.at.

We are certain that the papers presented at the ICSTI 2018 will enable us to make a significant contribution towards the sustainable development of the coke and ironmaking industry.

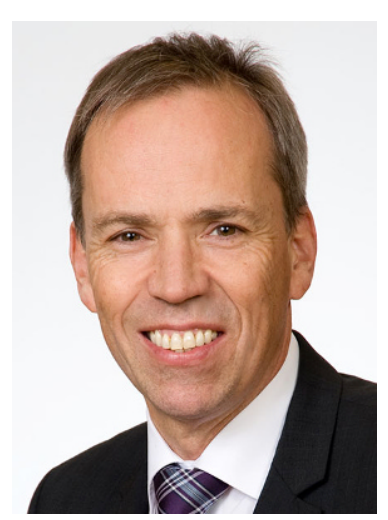

Johannes Schenk

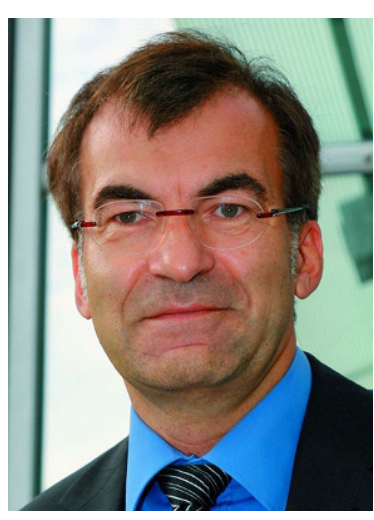

Bruno Hribernik

Johannes Schenk, Scientific Chairman Bruno Hribernik, Organisation Chairman 